\title{
ANÁlISE DE IMAGEM APLICADA AO PROCESSO DE SEPARAÇÃO SÓLIDO-LÍQUIDO EM PENEIRA VIBRATÓRIA NO PROCESSO DE PERFURAÇÃO DE POÇOS DE PETRÓLEO
}

\author{
T. S. A. SANTIAGO ${ }^{1}$, V. P. BARBOSA ${ }^{1}$, R. GEDRAITE $^{1}$ e C. H. ATAÍDE ${ }^{1}$ \\ ${ }^{1}$ Universidade Federal de Uberlândia, Faculdade de Engenharia Química \\ E-mail para contato: rgedraite@ufu.br
}

\begin{abstract}
RESUMO - Em processos de perfuração de poços de petróleo, o primeiro equipamento utilizado na separação do fluído de perfuração e do sólido proveniente do corte das rochas é a peneira vibratória. Este equipamento opera sob a influência de diversas variáveis, tais como: força-g, vazão de alimentação e concentração volumétrica de sólidos dentre outras. Neste trabalho é abordada a questão de como a análise de imagem pode ser utilizada no monitoramento e na avaliação do tamanho e da quantidade de conglomerados de partículas e do comportamento da suspensão mantida sobre a tela de separação da peneira vibratória. As imagens foram binarizadas e filtros foram aplicados de modo a permitir uma melhor caracterização dos conglomerados. Os resultados obtidos foram considerados satisfatórios.
\end{abstract}

\section{INTRODUÇÃO}

Durante o processo de perfuração de poços de petróleo, a broca de perfuração corta as rochas abrindo o poço, por onde o petróleo deverá escoar ao fim da perfuração. Durante este processo é utilizado o fluído de perfuração, que é injetado através do interior da coluna de perfuração e retorna a superfície através do espaço entre a coluna de perfuração e a parede do poço. Este fluído possui a finalidade estabilizar o poço, lubrificar a coluna de perfuração, arrefecer a broca, carrear os sólidos provenientes do corte das rochas, entre muitas outras (ASME 2005). Quando este fluído sobe a superfície, traz consigo uma grande quantidade de rocha fragmentada proveniente da matriz rochosa perfurada, sendo de extrema importância a separação dos sólidos do fluído de perfuração, para que este possa ser reciclado e continuamente utilizado durante o processo de perfuração do poço, sendo que o sólido deva ser descartado com a menor umidade residual possível, reduzindo, assim, o impacto ambiental.

A primeira etapa empregada na separação sólido-líquido aplicada ao fluído de perfuração e aos sólidos rochosos é a peneira vibratória, sendo que numa unidade típica de tratamento de fluído de perfuração, este equipamento é precedido de bateria de hidrociclones e centrífugas decantadoras (Lobato et al. 2011), sendo de grande importância o monitoramento deste equipamento, já que este possuí influência em todos os demais presentes na linha de tratamento do fluído de perfuração. 
As peneiras vibratórias evoluíram ao longo dos anos de equipamentos simples, capazes de processar apenas materiais grosseiros, até modernos equipamentos utilizados nos mais variados setores da indústria (Guerreiro et al. 2015). O monitoramento deste tipo de equipamento é difícil, assim como a modelagem fenomenológica, devido ao grande número de variáveis envolvidas no processo.

Com a finalidade de auxiliar no levantamento de como determinadas variáveis afetam o processo de peneiramento, o trabalho propõe a utilização do processamento de imagem focado à área da tela peneira.

A análise de imagem é uma ferramenta que vem produzindo resultados de grande relevância para a sociedade, tendo se mostrado muito eficiente em diversas aplicações (Matta, 2015).

Um dos objetivos da técnica de análise de imagem é a classificação dos objetos de acordo com suas dimensões, sendo que a captura destas imagens em ambientes reais, pode estar sobre interferência de diferentes fontes de luz e reflexões, o que torna necessário a aplicação de filtros de imagem para uma melhor análise (Matta, 2015). Estes filtros têm como objetivo a eliminação de ruídos e pixels isolados, que podem gerar uma análise de má qualidade do processo.

A análise de imagem é formada por diversas etapas, sendo a primeira a captura em vídeo ou foto do equipamento em funcionamento, seguido de: aplicações de filtros, transformação da imagem em tons de cinza e por último a binarização desta imagem, que consiste em transformá-la em tons de preto e branco puros (0 e 1)

A binarização da imagem permite a análise desta através da diferenciação dos níveis preto e branco em objeto e fundo, ou vice-versa. Para a realização desta etapa é necessário a definiçãa do threshold, que consiste num limite onde todos os pixels mais claros, na imagem (já em tons de cinza) que determinado tom de cinza serão considerados nível branco, desta forma todos abaixo, ou com mesmo tom que a limite escolhido, serão consideradas nível preto.

\section{MATERIAS E MÉTODOS}

Diversas etapas são aplicadas no processo de análise de imagem. Neste trabalho a primeira etapa realizada foi a captura em vídeo da tela de peneiramento durante o processo de separação sólido-líquido. Logo após, foram coletados frames do vídeo em tempos igualmente espaçados através do software ImageGrab 5.0.

Com o frame em mãos, foi utilizado o software imageJ para análise de imagem. Primeiramente o frame a ser analisado é aberto através do programa imageJ. A imagem em cores é transformada em tons de cinza, conforme mostrado na Figura 1. 


\section{Congresso Brasileiro de Engenharia Química em Iniciação Científica UFSCar - São Carlos - SP 16 a 19 de Julho de 2017}

Figura 1 - (A) Imagem em cores. (B) Imagem em tons de cinza

(A)

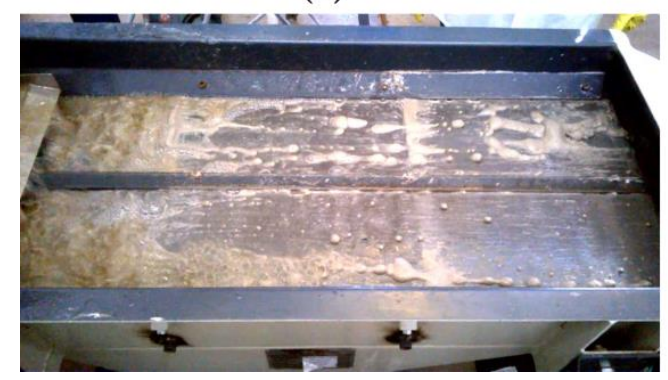

(B)

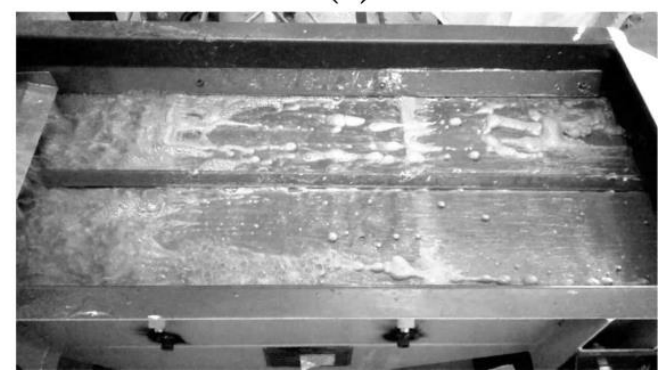

Em seguida, é feita a escolha da janela de utilização onde será aplicada a análise de imagem, conforme mostrado na Figura 2

Figura 2 - (A) - Imagem total. (B) - Janela de analise

(A)

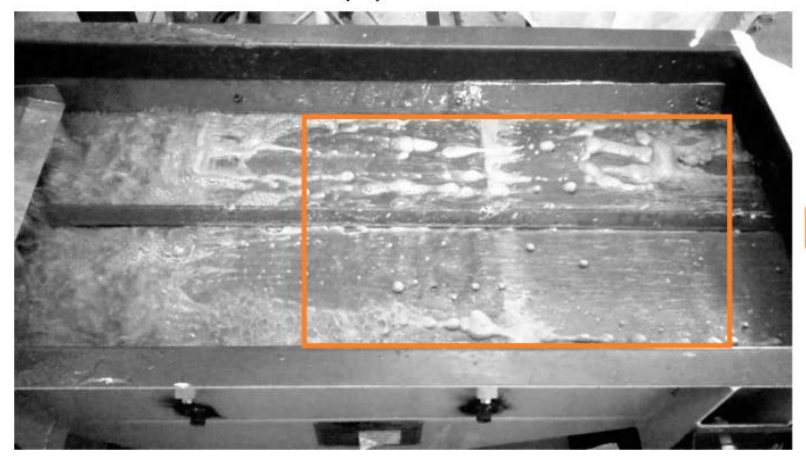

(B)

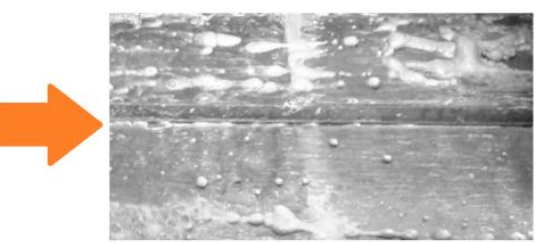

Após executadas as etapas anteriormente citadas, são ajustados o brilho, contraste e gama da imagem, também pelo imageJ. Como não é possível a eliminação de todos os ruídos indesejados simplesmente pela aplicação de filtros, ações manuais são necessárias em conjunto com estes. Estas ações manuais compreendem apagar bordas de baixa definição e eliminar os ruídos não "pegos" pelos filtros, simplesmente apagando-os com a ferramenta eraser do software e atribuindo com a ferramenta pencil a qual nível aquela área apagada pertence (fundo ou objeto), através da atribuição de uma cor. O threshold é ajustado e a binarização da imagem é feita.

Na Figura 3 podem ser visualizados os resultados típicos referentes à metodologia apresentada anteriormente, a título de exemplo. 
Figura 3 - (A) - imagem em tons de cinza, (B) - ajuste brilho, contraste e gama, (C) -utilização de filtros e ações manuais, (D) - binarização da imagem

(A)

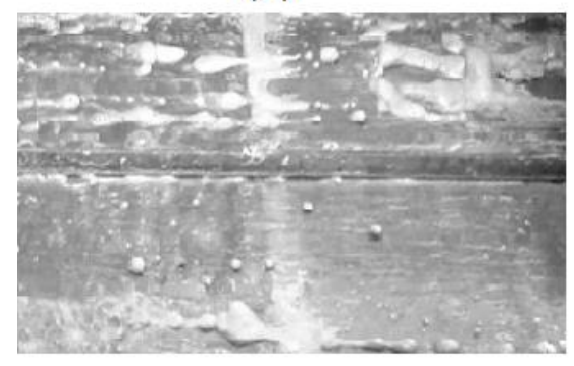

(C)

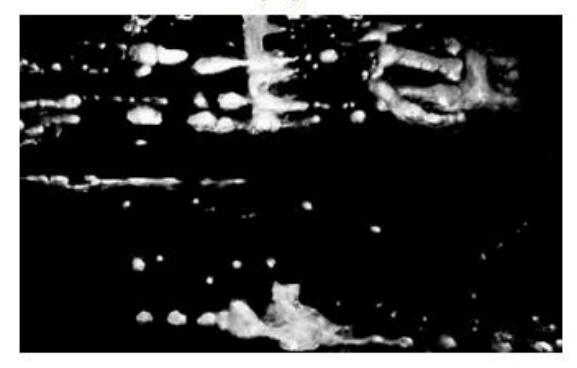

(B)

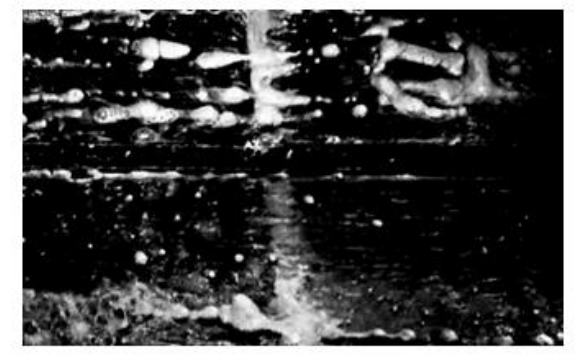

(D)

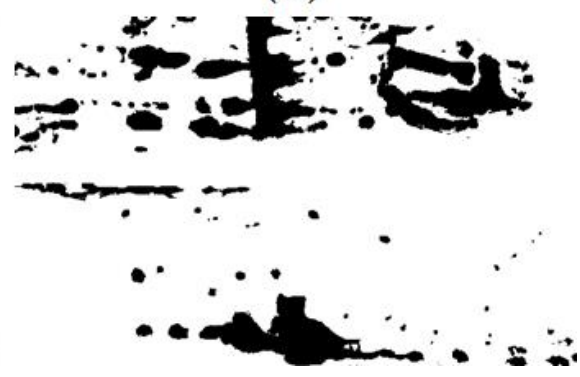

\section{RESULTADOS E DISCUSSÃO}

Com a imagem binarizada é possível analisar o número de conglomerados e a área que ocupam sobre a tela. A imagem analisada pelo aplicativo ImageJ, com os diferentes conglomerados, é mostrada na Figura 4.

Figura 4 -Imagem analisada pelo imageJ
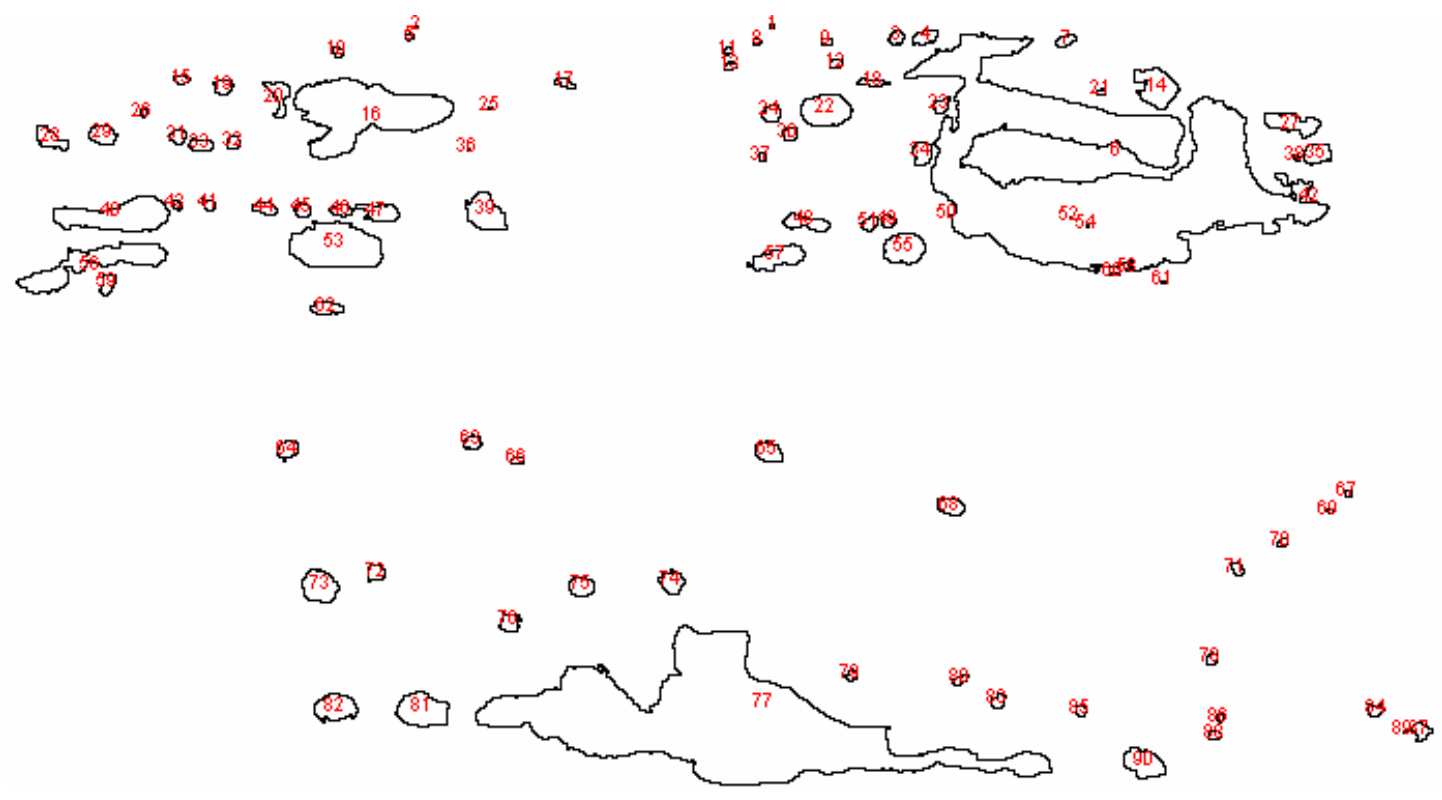
A porcentagem de área da tela de separação da peneira ocupada pelos conglomerados foi estimada pelo aplicativo ImageJ e corresponde a aproximadamente 14,98\%. Com estas medidas é possível relacionar como a área de tela ocupada pelo material sólido afeta o processo de separação sólido líquido em peneira vibratória, relacionando-a com as demais variáveis que participam do processo, tais como: força-g, vazão de alimentação da suspensão e concentração volumétrica de sólidos na corrente de alimentação.

Além disso, é possível estimar o número de conglomerados sobre a tela, e identificar se o tamanho destes varia de acordo com as condições operacionais. No exemplo acima foram identificados 115 conglomerados numa área de $1748,16 \mathrm{~cm}^{2}$. Esta área é medida através de uma escala que pode ser escolhida através da ferramenta set scale, permitindo o conhecimento da dimensão real da análise.

\section{CONCLUSÕES}

Pode-se concluir que a análise de imagem é um método bastante eficiente para a obtenção de dados referente à área ocupada pelo sólido no processo de peneiramento vibratório aplicado à separação sólido-líquido, garantindo uma medida confiável e a possibilidade de relacioná-la com outras variáveis do processo.

O trabalho permitiu o aprendizado na utilização de um aplicativo livre, simples de usar e que proporcionará o desenvolvimento em etapa futura de um algoritmo de processamento de imagem permitindo, com relativa eficiência, caracterizar os conglomerados de partículas presentes na suspensão alimentada. O tempo de resposta depende do número e combinação de filtros utilizados, que também podem ser desenvolvidos de acordo com as necessidades de análise e particularidades do processo.

\section{REFERÊNCIAS}

ASME - American Society of Mechanical Engineer, Drilling Fluid Processing Handbook. USA: Gulf professional publishing, Elsevier, 2005.

GUERREIRO, F. S., GEDRAITE, R., ATAÌDE, C. H., Residual moisture content and separation efficiency optimization in pilot-scale vibrating screen.Powder technol. , v. 287, p $301-307,2016$.

LOBATO, F. S., OLIVEIRA-LOPES, L. C., GEDRAITE, R., NEIRO, S. M. S., MURATA, V. Identificação de modelos para unidades de recuperação do fluído de perfuração. IV Encontro Nacional de Hidráulica de Poços de Petróleo e Gás, Foz do Iguaçu - PR, 2011.

MATTA, E. N. CIPELli, C. A. P., ASSiS, W. O., GOMES, M. M., BABRBOSA, V. P., ATAÍDE, C.H. Contribuição para o melhor aproveitamento de fluído de perfuração de poços de petróleo - Uma abordagem utilizando o processamento de imagem, Anais ENEMP 2015, 906 - 915, 2015. 


\section{AGRADECIMENTOS}

Os autores agradecem à UFU, ao CNPq e à PETROBRÁS pelos recursos concedidos e apoio em pesquisas no projeto referente ao termo de cooperação $\mathrm{N}^{\circ}$ 0050.0078502.12. 